\title{
Modeling Low Velocity Impact Response of Carbon Fiber Reinforced Aluminum Laminates (CARALL)
}

\author{
Gurpinder S. Dhaliwal ${ }^{1} \cdot$ Golam M. Newaz ${ }^{1}$
}

Received: 9 November 2015/Accepted: 31 January 2016/Published online: 8 February 2016

(C) Society for Experimental Mechanics, Inc 2016

\begin{abstract}
Fiber metal laminates (FMLs) have shown great potential in lightweight aerospace applications. Carbon fiber reinforced aluminum laminates (CARALL) is a lightweight system that has received less attention than aramid reinforced aluminum laminates. These FMLs have adhesively bonded layered plies. We have developed CARALL without the use of adhesives. The epoxy resin from the carbon fiber epoxy is used to adhesively bond the aluminum layers. In this study, CARALL laminates having a 3/2 configuration, with Aluminum 5052-H32 as the outer layer were prepared using a vacuum press without using any adhesive film. Primary failure modes observed were cracks in non-impacted aluminum layer, carbon fiber (CFRP) layer fracture and delamination between aluminum and CFRP layers. Finite element modeling was used to predict low velocity impact response of these FMLs by considering Chang-Chang damage criteria for CFRP layers and nonlinear elasto-plasticity along with progressive damage mechanics for aluminum layers. Delamination was modeled by using traction separation law and damage criterion proposed by Benzeggagh-Kenane was used for interface damage evolution. The damage size of CARALL FMLs was characterized using C-scan equipment and compared with the finite element predictions. Numerical simulation was used to predict load-displacement histories, delamination area, absorbed energy, damage morphologies on impacted and non-impacted sides and tensile failures of
\end{abstract}

Gurpinder S. Dhaliwal

gurpinder01@gmail.com

Golam M. Newaz

gnewaz@eng.wayne.edu

1 Department of Mechanical Engineering, Wayne State University, Detroit, MI, USA
CFRP layers for impact event at three different energy levels. Predicted impact behavior results match well with experimental results. The threshold impact energy, energy at which perforation failure was induced in all metallic and fiber reinforced layers for these CARRAL laminates was found to be around $31 \mathrm{~J}$.

Keywords CARALL - Low velocity impact test - FEM · C-scan

\section{Introduction}

Fiber metal laminates (FMLs) are lightweight structural materials developed with the combination of alternating thin, high strength metallic sheets and fiber reinforced adhesive layers. Currently, fiber metal laminated composites are mainly used in aerospace industry specifically due to their increased stiffness and strength in comparison to aluminum. Examples of application of FMLs in aerospace industry are aramid reinforced aluminum laminates (ARALL) to be used as material for the highly fatigue rear cargo door of the C-17 cargo aircraft to reduce overall weight and glass reinforced aluminum laminates (GLARE) panels in the upper fuselage of the Airbus A380 commercial aircraft $[1,2]$. Due to the excellent impact properties of GLARE, it has also been used as a surface material in the Boeing 777 cargo floor panels [3]. Several research studies have shown that FMLs have excellent impact resistance of metals and attractive properties of fiber reinforced composites [3-6].

Many research studies have been conducted in recent years to study mainly the low and high velocity impact response of GLARE and ARALL [7, 8]. Very few research papers are found in literature that describes the low 
velocity impact behavior of CARRAL FMLs [9-15]. Abdullah et al. [7] investigated the impact behavior of a polypropylene based glass fiber reinforced FML and their results showed that the energy is absorbed by FMLs through plastic deformation in aluminum and microcracking in the composite layers. Caprino et al. [8] studied the low-velocity impact performance of GLARE composites made of 2024 T3 sheets and S2-glass/epoxy prepreg layers and showed that the overall force-displacement curve only depends on the impact energy, rather than on the mass and speed separately. Their results show that GLARE seems to offer better performance in terms of penetration energy and damage resistance than carbon fiber and glass fiber-reinforced laminates.

Carbon fiber can offer more efficient crack bridging to aluminum layers than aramid fiber and glass fiber due to their high stiffness and CARALL FMLs also provide excellent impact resistance due to the presence of aluminum layer. CARALL provides excellent advantage to use as a material for helicopter, robot, laminated pipe, drive shaft and aircraft structural components due to presence of a combination of high stiffness and strength with good impact resistance [10-12]. Bieniaś et al. [9] investigated the resistance to low velocity impact of aluminum alloys and a carbon/epoxy composite laminates. Their results show that the ply orientation in unidirectional carbon/ epoxy and aluminum laminates has particularly importance for their impact resistance. Yu et al. [13] studied the effect of the properties of aluminum alloy on the low velocity impact response of CARALL and showed that the impact resistance of CARALL is improved by increasing the yield strength of aluminum alloy.

However, only few researchers have employed the finite element method to perdict the low velocity impact response of CARALL FMLs. In particular, there is no data for CARALL made without the use of adhesive bond. So primary focus of this research was to employ two dimensional (2D) finite element modeling in thickness direction for predicting impact response of this class of CARALL FMLs and comparing it with experimental drop weight test at different impact energies.

\section{Specimen Preparation}

Aluminum alloy 5052-H32 sheets having $0.5 \mathrm{~mm}$ thickness (with $96.85 \% \mathrm{Al}, 0.25 \%$ of $\mathrm{Fe}, 2.50 \%$ of $\mathrm{Mg}, 0.07 \%$ of $\mathrm{Mn}, 0.11 \%$ of $\mathrm{Si}, 0.01 \%$ of $\mathrm{Zn}, 0.01 \%$ of $\mathrm{Cu}$ and $0.20 \%$ of Cr) and VTM 264/CF302 woven carbon fiber/epoxy prepreg supplied by CYTEC having $0.22 \mathrm{~mm}$ thickness and $42 \%$ fiber volume fraction were the materials used for the manufacturing of FML specimens. Grit paper \# 60/P60 was only used to make the surface of aluminum sheet slightly rough so as to increase the interlocking between the carbon fiber and aluminum layers. A schematic illustration of FML specimen is shown in Fig. 1.

Hand layup method was employed to fabricate the specimens followed by using autoclave vacuum press machine for curing. During the curing process the layered prepreg and aluminum system was kept in vacuum and $0.35 \mathrm{MPa}$ pressure was applied on the layered system at $130{ }^{\circ} \mathrm{C}$ for $60 \mathrm{~min}$. Autoclave vacuum press equipment allows to apply pressure between 0 and $0.35 \mathrm{MPa}$ during the curing of composites. From our experience with CFRP laminates, it was assured that $0.35 \mathrm{MPa}$ will be a good pressure for the consolidation of CARALL FMLs. The carbon fiber/epoxy and aluminum layered system was then cooled by passing mist and water over the platen for $15 \mathrm{~min}$ each.

\section{Experimental Procedures}

ASTM standard D7136 [16] was referred to investigate the low velocity impact behavior of FMLs. Drop-weight impact tests on CARALL FMLs were performed using a hemispherical striker having a weight of $1.819 \mathrm{~kg}$ and a tip diameter of $28.39 \mathrm{~mm}$. Rectangular specimens with dimensions of $152.4 \times 101.6 \mathrm{~mm}^{2}$ were clamped to a $20 \mathrm{~mm}$ thick aluminum plate having a $125 \mathrm{~mm} \times 75 \mathrm{~mm}$ cutout located at the center with the help of four toggle clamps having a minimum holding capacity of $1100 \mathrm{~N}$.

The tips of the clamps were made of neoprene rubber with a durometer of 70-80 Shore A. Guide pins were used to position the specimen centrally over the cutout. The fixture was aligned to a rigid base using bolts. A representative base design is shown in Fig. 2a. The designated impact energy was obtained by adjusting the height of the hemispherical impactor. The velocity of the impactor nose was measured with the help of accelerometer located on the top of striker. The contact force between the impactor and the sample was measured by utilizing load cell located underneath the rigid

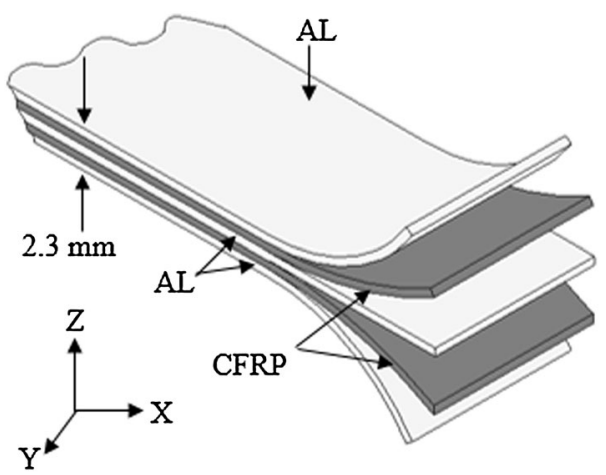

Fig. 1 Schematic illustration CARALL FMLs with 3/2 Layup sequence. (AL stands for aluminum layer and CFRP stands for carbon fiber/epoxy layer) 

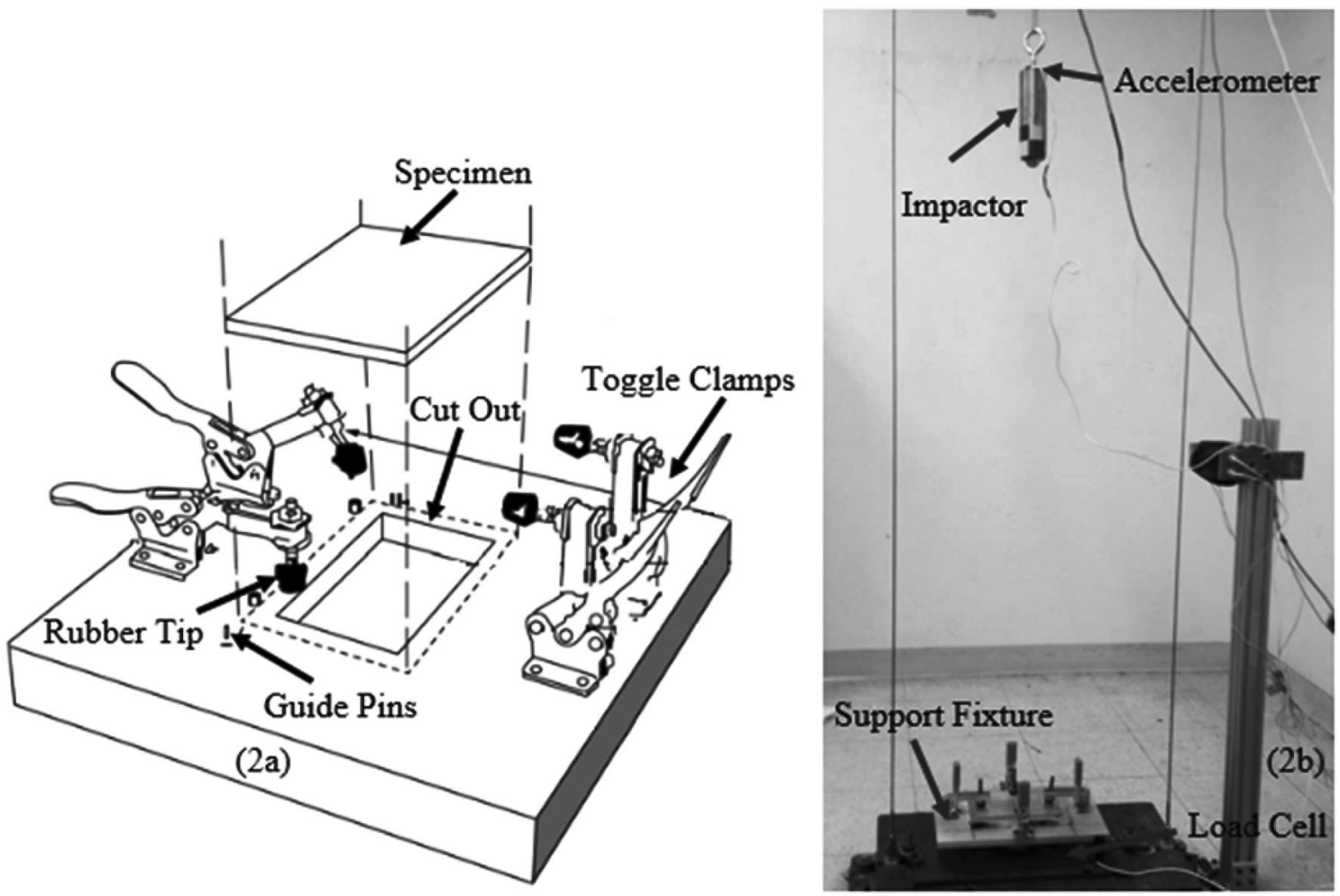

Fig. 2 Impact support fixture and test tower [16]

support fixture. The acceleration-time signal measured by the acquisition system was integrated twice to obtain the displacement. The impact acceleration-time and force-time relation were obtained for each impact event. The CARALL FMLs were experimentally tested at impact energies of 14 , 21 and $31 \mathrm{~J}$ by utilizing the drop weight impact tower shown in Fig. 2b. An assumption of no energy loss was made in the calculations for the contact force between the striker tip and sample during the impact event. Some specimens were carefully sliced through the center to observe the damage behavior through the laminate thickness with the help of cross-sectional microscopy. All the laminates were scanned with the C-scan equipment prior to testing to check the presence of any interface bonding defects between CFRP and aluminum layers. The results were excellent showing good bonding at all interfaces.

The presence of epoxy resin layer between successive CFRP and aluminum layers was also observed by using SEM imaging technique in all FMLs. This epoxy resin layer will act as barrier between CFRP and aluminum layers and help to hinder the occurrence of galvanic corrosion on aluminum layers. The cross section of CARALL fiber metal laminate sample was carefully cut by using diamond cutter and polished by using sand paper \# 1200 . The presence of epoxy resin layer with $4 \mu \mathrm{m}$ average thickness between adjacent CRFP and aluminum layer is shown in Fig. 3:

\section{Finite Element Modeling}

The low velocity impact response of CARALL FMLs were modeled with the help of commercially available LSDYNA software by using explicit time integration scheme. The development of finite element (FE) model for impact simulations in LS-DYNA includes discretization of sample geometry into finite elements, modeling of composite material including intralaminar failure and delamination failure, modeling of aluminum material with strain based

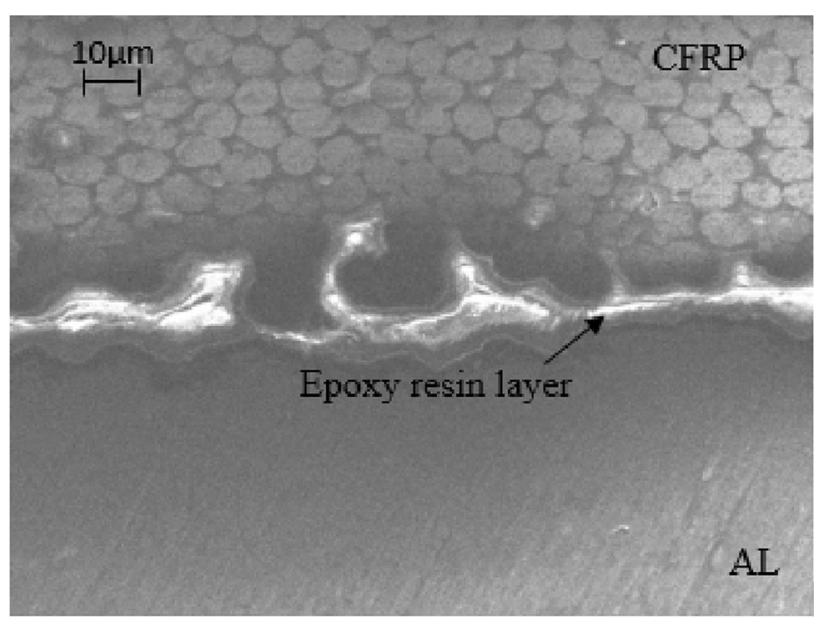

Fig. 3 SEM image of CARALL's cross section 
failure criteria and modeling of rigid hemispherical striker with appropriate contact algorithm and boundary conditions.

\section{Discretization of FML Specimen}

In this study, the thickness of aluminum layers was modeled using two dimensional selective reduced (S/R) integrated continuum linear shell elements with four nodes (ELFORM 2). The thickness of CFRP plies was also represented with two dimensional selective reduced (S/R) integrated linear shell elements considering one layer of shell elements for each lamina with three integration points with respect to ply thickness. Entire FE model of FML specimen is based on the shell elements and each layer consisting of shell elements builds up the thickness of FML specimen. The through thickness stresses were not taken into consideration by using shell elements in this analysis. The total number of elements in FE model for each aluminum and CFRP layer are 15606. Finite element mesh was generated using square element with $\Delta$ side of $1.0 \mathrm{~mm}$ for both aluminum and CFRP layers having $152.4 \mathrm{~mm} \times 101.6 \mathrm{~mm}$ geometric dimensions. The finite element model of CARALL FML with a detailed view of tiebreak interface contacts between adjacent layers is shown in Fig. 4.

A stiffness-based hourglass control (IHQ = 4) was used for the aluminum layers, and an hourglass control $(\mathrm{IHQ}=8)$ for the laminas, which activates the full-projection warping stiffness for more accurate results. Hourglass control is viscosity or stiffness that is added to selective reduced integrated quadrilateral shell elements or hexahedral solid elements to prevent zero-energy modes of deformation that produce zero strain and no stress. Without hourglass control, these elements will have nonphysical hourglass modes which could grow large and destroy the solution. Two different types of hourglass formulations were chosen considering the material models used to model aluminum and CFRP layers. A stiffness based hourglass formulation (IHQ $=8$ ) have algorithm to activate warping stiffness also, due to which it gives more accurate results for orthotropic materials than hourglass formulation $(\mathrm{IHQ}=4)$. The value of hourglass coefficient $(\mathrm{QH}=0.05)$ was kept similar in both hourglass formulations.

\section{Aluminum Material Model}

The piecewise linear plasticity material model (Mat_024) was utilized to model elasto-plastic behavior of aluminum layers by defining effective stress-effective plastic strain curve obtained from tensile test conducted at a strain rate of $0.05 \mathrm{~mm} / \mathrm{s}$ as shown in Fig. 5. This is also a model flow stress curve for our analysis. The failure of aluminum layers was modeled in this study by defining a plastic failure strain in constitutive model card of LS-DYNA. In the constitutive equations of this material model, the plasticity treatment includes strain rate and yield function is traditionally defined by Eq. 1 .

$\emptyset=\frac{1}{2} S_{i j} S_{i j}-\frac{\sigma_{y}^{2}}{3} \leq 0$

Where

$\sigma_{y}=\beta\left[\sigma_{0}+f_{h}\left(\varepsilon_{\mathrm{eff}}^{p}\right)\right]$

The effective plastic strain is defined as $\varepsilon_{e f f}^{p}=$ $\int_{0}^{t}\left(\frac{2}{3} \dot{\varepsilon}_{i j}^{p} \dot{\varepsilon}_{i j}^{p}\right)^{1 / 2} \mathrm{~d} t$ and $\sigma_{0}$ denotes the initial yield strength. The plastic strain rate $\dot{\varepsilon}_{i j}^{p}$ is the difference between the total and elastic strain rates. The strain rate effects can be included in this model by using the Cowper-Symonds model which scales the yield stress with the factor $\beta$.

$\beta=1+\left(\frac{\dot{\varepsilon}}{C}\right)^{1 / p}$

Where $C$ and $p$ are the constants of user defined input constants. The complete mathematical equations for piecewise linear plasticity material model can be found in LS-DYNA theory manual [17].

However, we have not used any strain rate and hardening effects in our analysis. This assumption is good for aluminum material subjected to low velocity impact loading which is our focus. Aluminum is not strain rate sensitive at low velocity impact levels. Therefore, the value of $\beta$ is not likely to change for aluminum at low velocity mechanical loadings. The implementation of the piecewise linear plasticity model is done in LS-DYNA by updating the deviatoric stresses elastically, checking the yield function and the deviatoric stresses are accepted if the yield function is satisfied. The incremental plastic strain is computed if the yield function is not satisfied. The trial deviatoric stress state, $S_{i j}^{*}$ is then scaled back. The material properties parameters of 5052-H32 aluminum alloy used for predicting impact behavior of FMLs are presented in Table 1. The mechanical properties of 5052-H32 aluminum alloy shown in Table 1 were evaluated experimentally with tensile test performed in the lab and crosschecked with the values given in Ref. [18].

\section{Composite (CFRP) Material Model}

The material properties of carbon fiber/epoxy layers, which were provided by CYTEC are shown in Table 2 [19]. The impact response of the woven carbon fiber/epoxy layers was modeled using Chang-Chang [20] damage initiation 


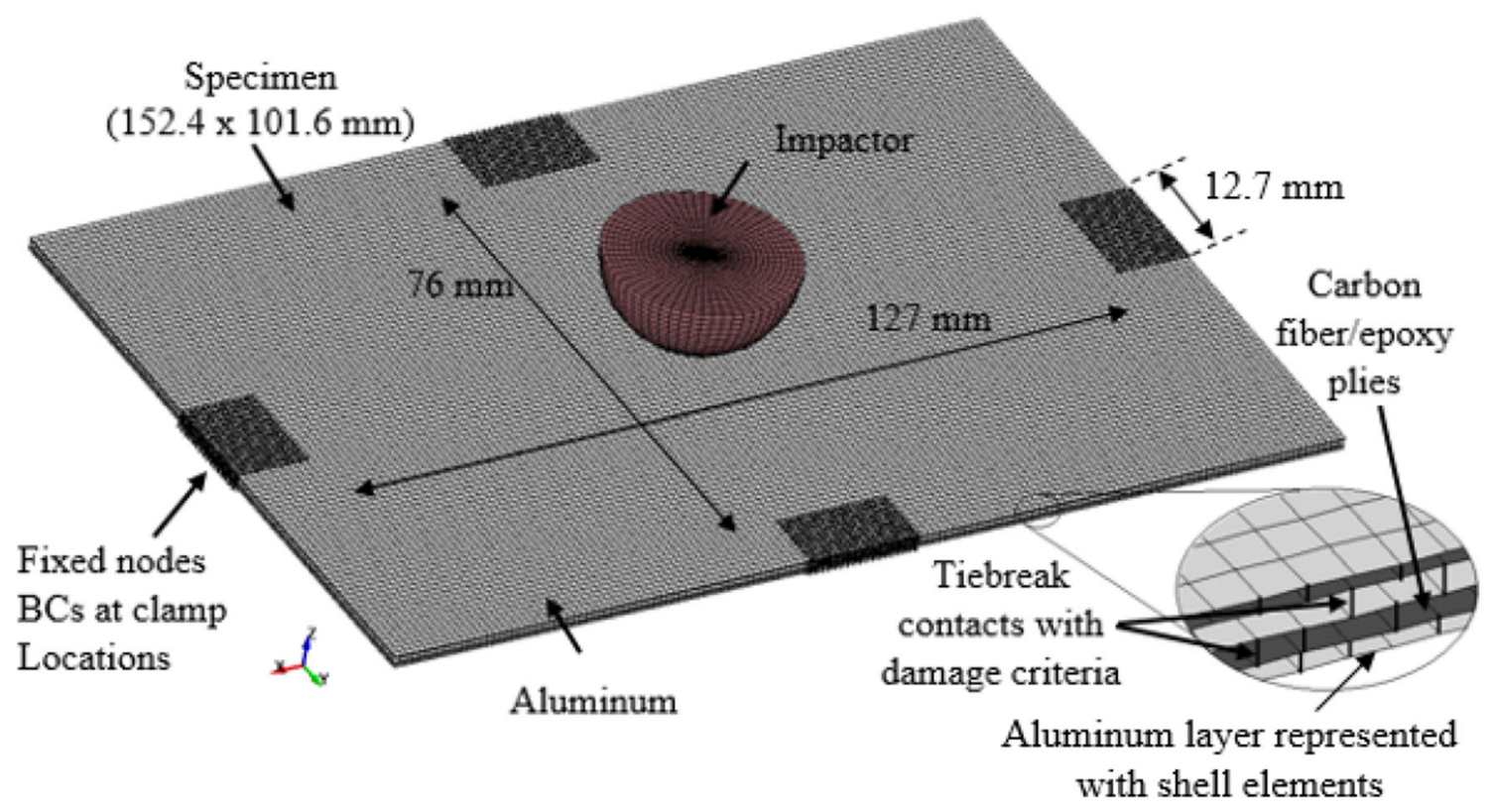

Fig. 4 Details of finite element model for impact simulation as in actual experiments

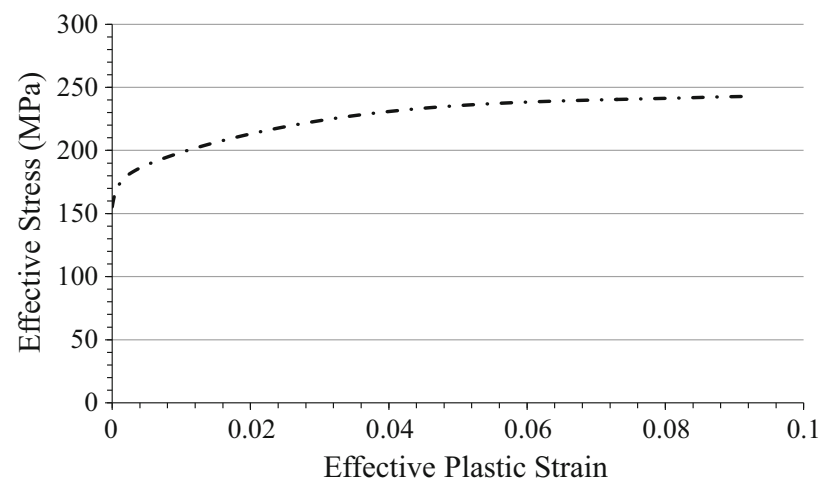

Fig. 5 Effective stress-effective plastic strain used as input to constitutive material model

criteria inbuilt in Enhanced Composite Damage (Mat_054) material model of LS-DYNA. According to this failure criteria, a damage in composite laminate occurs when one of the following failure equation is equal to or greater than zero. Fiber tension, fiber compression, matrix tension and matrix compression are the four failure modes considered in Chang-Chang failure criteria [20]. The failure equations are referenced from LS-DYNA user keyword manual, volume-II [21] and represented separately as follows:
Tensile failure, fiber mode $: \mathrm{e}_{\mathrm{f}, \mathrm{T}}^{2}$

$$
\begin{aligned}
= & {\left[\frac{\sigma_{1}}{X_{T}}\right]^{2}+\phi\left[\frac{\tau_{12}}{S_{c}}\right] } \\
& -1\left\{\begin{array}{l}
\geq 0 \text { failure } \\
<\text { 0elastic }
\end{array}\right.
\end{aligned}
$$

Compressive failure, fiber mode : $\mathrm{e}_{\mathrm{f}, \mathrm{C}}^{2}$

$$
=\left[\frac{\sigma_{1}}{X_{c}}\right]^{2}-1\left\{\begin{array}{l}
\geq 0 \text { failure } \\
<0 \text { elastic }
\end{array}\right.
$$

Tensile failure,matrixmode $: \mathrm{e}_{\mathrm{m}, \mathrm{T}}^{2}$

$$
=\left[\frac{\sigma_{2}}{Y_{T}}\right]^{2}+\left[\frac{\tau_{12}}{S_{c}}\right]^{2}-1\left\{\begin{array}{l}
\geq 0 \text { failure } \\
<0 \text { elastic }
\end{array}\right.
$$

Compressive failure,matrix mode : $\mathrm{e}_{\mathrm{m}, \mathrm{C}}^{2}$

$$
=\left[\frac{\sigma_{2}}{2 S_{c}}\right]^{2}+\frac{\sigma_{2}}{Y_{c}}\left[\frac{Y_{c}^{2}}{4 S_{c}^{2}}-1\right]+\left[\frac{\tau_{12}}{S_{c}}\right]^{2}-1\left\{\begin{array}{l}
\geq 0 \text { Ofailure } \\
<0 \text { olastic }
\end{array}\right.
$$

Where $\sigma_{1}$ is the nominal stress in the lamina in the longitudinal direction, $\sigma_{2}$ is the nominal stress in the lamina in the transverse direction, $\tau_{12}$ is the nominal shear stress in the plane of lamina, $X_{T}$ is the tensile strength in the longitudinal direction, $X_{c}$ is the compressive strength in the
Table 1 5052-H32 Aluminum alloy and steel impactor properties

\begin{tabular}{lllllll}
\hline Material & $\rho\left(\mathrm{kg} / \mathrm{m}^{3}\right)$ & $\mathrm{E}(\mathrm{GPa})$ & $\sigma_{\mathrm{y}}(\mathrm{MPa})$ & $v$ & $\mathrm{G}(\mathrm{GPa})$ & Plastic failure strain \\
\hline Aluminum & 2680 & 70.3 & 160 & 0.33 & 26.4 & 0.09 \\
Steel (Impactor) & 7800 & 210 & & 0.33 & & \\
\hline
\end{tabular}


Table 2 Twill weave carbon fiber/epoxy properties

\begin{tabular}{llllllllllll}
\hline Material & $\rho\left(\mathrm{kg} / \mathrm{m}^{3}\right)$ & $\mathrm{E}_{11}(\mathrm{GPa})$ & $\mathrm{E}_{22}(\mathrm{GPa})$ & $v_{21}$ & $\mathrm{G}_{12}(\mathrm{GPa})$ & $\mathrm{G}_{23}(\mathrm{GPa})$ & $\begin{array}{l}\mathrm{X}_{\mathrm{c}} \\
(\mathrm{MPa})\end{array}$ & $\mathrm{Y}_{\mathrm{c}}$ & $\mathrm{X}_{\mathrm{T}}$ & $\mathrm{Y}_{\mathrm{T}}$ & $\mathrm{S}_{\mathrm{c}}$ \\
\hline CFRP Layer & 1600 & 60 & 60.5 & 0.05 & 3.90 & 2.30 & 540 & 560 & 700 & 745 & 95 \\
\hline
\end{tabular}

longitudinal direction, $\mathrm{Y}_{\mathrm{T}}$ is the tensile strength in the transverse direction, $\mathrm{Y}_{\mathrm{c}}$ is the compressive strength in the transverse direction, $S_{c}$ is the shear strength, $\Phi$ is the shear stress correction parameter in the tensile failure mode. The value of $\Phi$ equal to zero was considered in the finite element analysis performed in this research study. The failure strains can also be applied in addition to these stress based failure criteria's. If strain based failure criteria is utilized, the stress value is kept at a constant level after meeting the Chang-Chang criteria until the failure strains are reached. The element is removed from the calculation when the stress based Chang-Chang failure criteria is met or failure strain reaches its maximum value. In this study failure strains for CFRP layers were not used.

\section{Delamination Failure Modeling}

Delamination is the one of the main sources of damage in the FMLs, separation of plies in low resistance interface between adjacent layers under compressive loading or impacts. The linear fracture mechanics techniques (LEFM) like virtual crack extension [22], the J-integral [23], the virtual crack closure (VCC) [24, 25] and the stiffness derivative [26] based on Griffith criteria [27] can be used to predict delamination in laminated composites in the absence of any nonlinearities. These methods are restricted to problems where initial crack is known, therefore these methods cannot be used to predict the initiation of delamination [28].

Damage mechanics and/or softening plasticity combined with indirect introduction of fracture mechanics based methodologies have been developed to model the mechanical response of interface [29-35]. Cohesive zone model is one of these methodologies which may be considered to be developed from the work of Hillerborg et al. [29]. In this research work, intralaminar delamination between the CFRP and aluminum layers was modeled by employing tiebreak algorithms available in LS-DYNA [36]. The transmission of both compressive and tensile forces is allowed in these penalty-based contact algorithms which are used to model connection between surfaces. The tie-break contact algorithms prevent the separation of the slave node from the master segment before failure of connection and after the failure the contact behaves like surface to surface contact with thickness offsets due to removal of tensile coupling. Depending upon the nature of connection, an optional failure criterion can be defined in all tie-break contacts. In this study, an extended form of dycoss discrete crack failure [37-41] criteria which is based on the fracture model defined in a cohesive material that includes a bilinear traction separation law with quadratic mixed mode delamination criterion and a Benzeggagh-Kenane [42] damage propagation formulation was used. The distance between two points initially in contact in the normal and tangential directions corresponds to complete material failure referred as ultimate displacements in the interface cohesive model. The linear stiffness for loading followed by the linear softening during the damage provides a simple relationship between the energy release rates, the peak tractions, and the ultimate displacements [21] given by Eqs. 8 and 9.

$\begin{aligned} G_{I C} & =\frac{T \times U N D}{2} \\ G_{I I C} & =\frac{S \times U T D}{2}\end{aligned}$

Where UND is the ultimate displacement in the normal direction; UTD is the ultimate displacement in the tangential direction, $\mathrm{G}_{\mathrm{IC}}$ is the Mode I energy release; $\mathrm{G}_{\mathrm{IIC}}$ is the Mode II energy release; $\mathrm{T}$ is the peak traction in normal direction and $\mathrm{S}$ is the peak traction in tangential direction.

In the cohesive material model, the total mixed mode relative displacement $\delta_{m}$ is defined as

$\delta_{m}=\left(\delta_{I}^{2}+\delta_{I I}^{2}\right)^{1 / 2}$

Where $\delta_{I}=\delta_{3}$ (Fig. 6) is the separation in the normal direction (Mode I) and $\delta_{I I}=\left(\delta_{1}^{2}+\delta_{2}^{2}\right)^{1 / 2}$ is the separation in the tangential direction (Mode II) and the damage initiation displacement $\delta_{0}$ for the mixed mode delamination (onset of softening) is given by Eq. 11.

$\delta_{0}=\delta_{I}^{0} \delta_{I I}^{0} \sqrt{\frac{1+\psi^{2}}{\left(\delta_{I I}^{0}\right)^{2}+\left(\psi \delta_{I}^{0}\right)^{2}}}$

Where $\delta_{I}^{0}=T / E N$ and $\delta_{I I}^{0}=S / E T$ are the single mode damage initiation separations, $\psi=\delta_{I I} / \delta_{I}$ is the "mode mixity" (Fig. 6); EN is the stiffness normal to the plane of interface; ET is the stiffness in the plane of interface. The ultimate mixed mode displacement $\delta^{F}$ (total failure) was used according to the Benzeggagh-Kenane law given in Eq. 12. 


$$
\begin{aligned}
\delta^{F}= & \frac{2}{\delta^{0}\left(\frac{1}{1+\psi^{2}} E N^{\gamma}+\frac{\psi^{2}}{1+\psi^{2}} E T \gamma\right)^{1 / \gamma}} \\
& \times\left[G_{I C}+\left(G_{I I C}-G_{I C}\right)\left(\frac{\psi^{2} E T}{E N+\psi^{2} E T}\right)^{X M U}\right]
\end{aligned}
$$

Where XMU is the exponent of mixed mode criteria and $\gamma$ is additional exponent for Benzeggagh-Kenane law. Although the computational cost was increased by modeling each layer with a separate shell elements but the ability to predict the delamination damage with greater accuracy was offered by this approach. The adhesion properties of aluminum and CFRP layers bond used as input to tiebreak contact in the simulation are given in Table 3. The values of peak tractions in normal and tangential directions were determined experimentally through T-peel and double notch shear strength tests. Mode I energy release rate were calculated from T-peel test data using area method given by Eq. 13 whereas Mode II energy release rate and mixed mode damage criteria exponent (XMU) values were assumed after referring to the work of Shin and Kim [43]. The values of the rest of the parameters were kept to their defaults settings as described in Table 3.

$G=\frac{1}{b}\left[\frac{\Delta E}{\Delta a}\right]$

where $\mathrm{b}$ is the width of the sample, $\Delta \mathrm{E}$ is the area under the load displacement curve and $\Delta \mathrm{a}$ is the crack extension.

A negative sign of XMU parameter invokes the B-K damage propagation model. The normal stiffness (EN) was not provided explicitly to the damage model. Penalty stiffness (default) was used by the model as the normal stiffness. The ET2EN parameter is defined as the ratio of the tangential stiffness to the normal stiffness in the B-K damage evolution formulation.

The impactor was meshed with 8-node linear brick, reduced-integration solid elements and modeled as hemispherical rigid body using rigid material model (Mat_020) with steel material properties as given in Table 1. The impactor was constrained to move only in $\mathrm{z}$ direction through material model card and a prescribed initial velocity was assigned to it to get desired impact energy. The penalty formulation based surface to surface contact was applied for the interaction of impactor with impacted plate and each contacted ply of the laminate by setting SOFT option of contact card to equal to 2 . The specimen nodes were constrained in all directions located at the toggle clamp locations so as to match the experimental boundary conditions as described in Fig. 4. A friction coefficient, $\mu=0.3$ was applied for the contact between impactor and the laminate.

\section{Results and Discussions}

The typical force displacement (F-D) response of CARALL is compared with finite element predictions at different impact energies in Fig. 7. The predictions made through FEM analysis are shown in dashed lines and the experimental results are plotted in solid lines.

A gaussian data smoothing technique was used over the experimental data to remove the noise captured by acquisition system during impact test. Each F-D curve has an ascending portion of loading known as bending stiffness due to the resistance of the composite to impact loading, the peak load value and descending section of unloading. The closed type F-D curves of CARALL FMLs for all impact energies imply that complete penetration and perforation was not observed in this study. The finite element predictions showed acceptable agreement with the experimental results for the ascending portion of the F-D curves but demonstrated some discrepancies in the unloading section for 21 and $31 \mathrm{~J}$ impact energies which may be due to the failure of present finite element material model to
Fig. 6 Mixed-mode tractionseparation law [38]

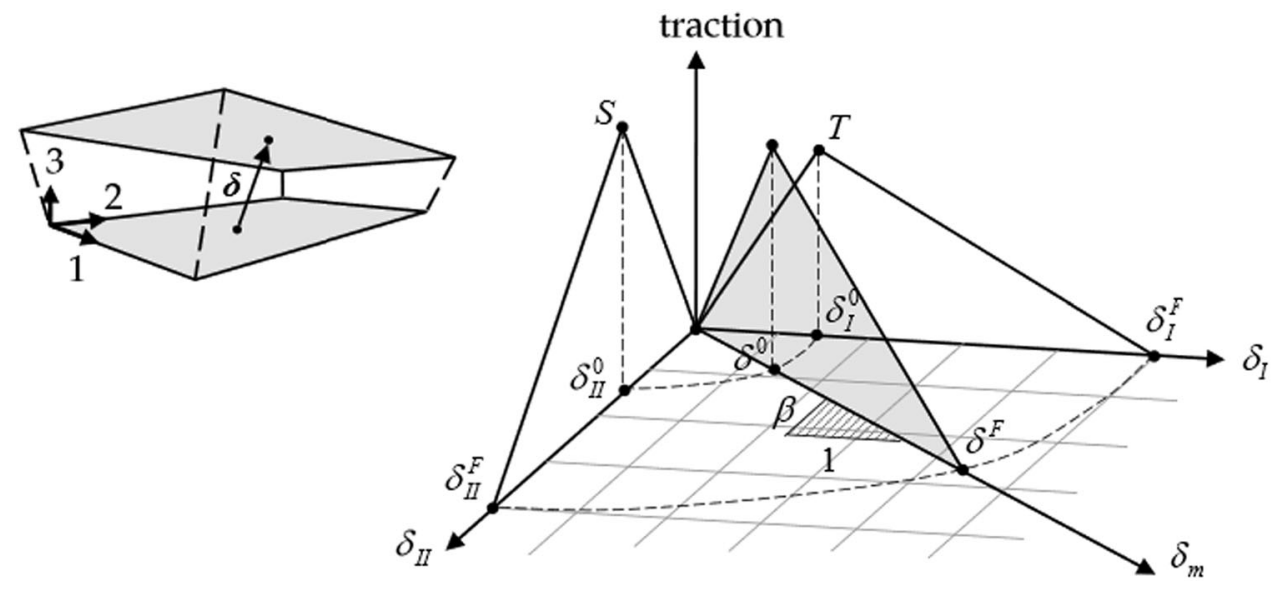


Table 3 Delamination damage model input data

\begin{tabular}{llllllll}
\hline $\mathrm{T}(\mathrm{MPa})$ & $\mathrm{S}(\mathrm{MPa})$ & $\mathrm{G}_{\mathrm{IC}}(\mathrm{MPa} \times \mathrm{mm})$ & $\mathrm{G}_{\mathrm{IIC}}(\mathrm{MPa} \times \mathrm{mm})$ & $\mathrm{ET} 2 \mathrm{EN}$ & $\mathrm{XMU}$ & $\mathrm{EN}$ & $\gamma$ \\
\hline 20 & 15 & 0.18 & 0.23 & 1 & -1.4 & Default & 1 \\
\hline
\end{tabular}

capture behavior of FMLs in unloading portion due to complex damage modes of FMLs.

The peak load values were found to be $5789,6777.8$ and $7171 \mathrm{~N}$ for 14,21 and $31 \mathrm{~J}$ impact energies, respectively. The low increase in peak load value from 21 to $31 \mathrm{~J}$ may be due to more delamination and excessive crack in metallic layers. The damage morphologies of CARALL specimens are evaluated at impacted and non-impacted side for all the impact energies and compared with FEA views as shown in Fig. 8. The CARALL specimens were cut carefully with diamond cutter along the main crack direction to observe the inner damage behavior and the cross-section images of damaged specimens were also examined and compared with FEA model as shown in Fig. 9.

For the lowest impact energy, minor cracks were observed at the non-impacted side aluminum layers in CARALL specimens. However, the primary damage modes are indentation-induced, fiber fracture and adhesive delamination at the aluminum carbon fiber/epoxy interfaces as shown by the cross section images in Fig. 9. As the impact energy increases to $21 \mathrm{~J}$, the crack lengths on the non-impacted side of CARALL specimens increases, along with indentation depth. Comparatively to previous impact energy, larger adhesive delamination, fiber and matrix fracture was observed in the CARALL FMLs specimens as shown by cross-section images in Fig. 9. With the further increase in the impact energy to $31 \mathrm{~J}$, resulted in much larger increase in crack lengths on the non-impacted sides of CARALL specimens. At this energy level, the indentation induced cracks in top aluminum metallic layer was also found in CARALL specimens as shown in Fig. 8. The failure of interior metallic aluminum layers and carbon fiber/epoxy layers to a much larger extent can also be observed in cross section images at this impact energy.

The delamination damage size was characterized by using C-scan equipment and compared with the finite element simulation results (Fig. 10) for CARALL specimens. In FEM predictions shown in Fig. 10, the solid blue color represent that damage is critical (value nearly 0.0 ) and the red color represent that the damage has not occurred (value nearly 1.0), and others represent different damage states. Similarly, the fully delaminated and no delamination regions in the $\mathrm{C}$-scan results are described by the 100 and $0 \%$ values of the legend, respectively. ImageJ image processing and analysis software was used to measure the delamination area from the $\mathrm{C}$-scan pictures. The damaged area is initially small, and gradually gets larger with increasing impact energy. Bilinear traction separation law with quadratic mixed mode delamination initiation criterion used in this study was found to successfully capture the delamination area giving a good match with the C-scan experimental results at lower impact energies. The perforation failure of FML layers dominates over the delamination failure between the adjacent layers at higher impact energy. However, there is a local delamination between CFRP and aluminum layers in the impact zone as can be observed in the cross section views described in Fig. 9. The FEM model also
Fig. 7 Force displacement history plots for CARALL specimens

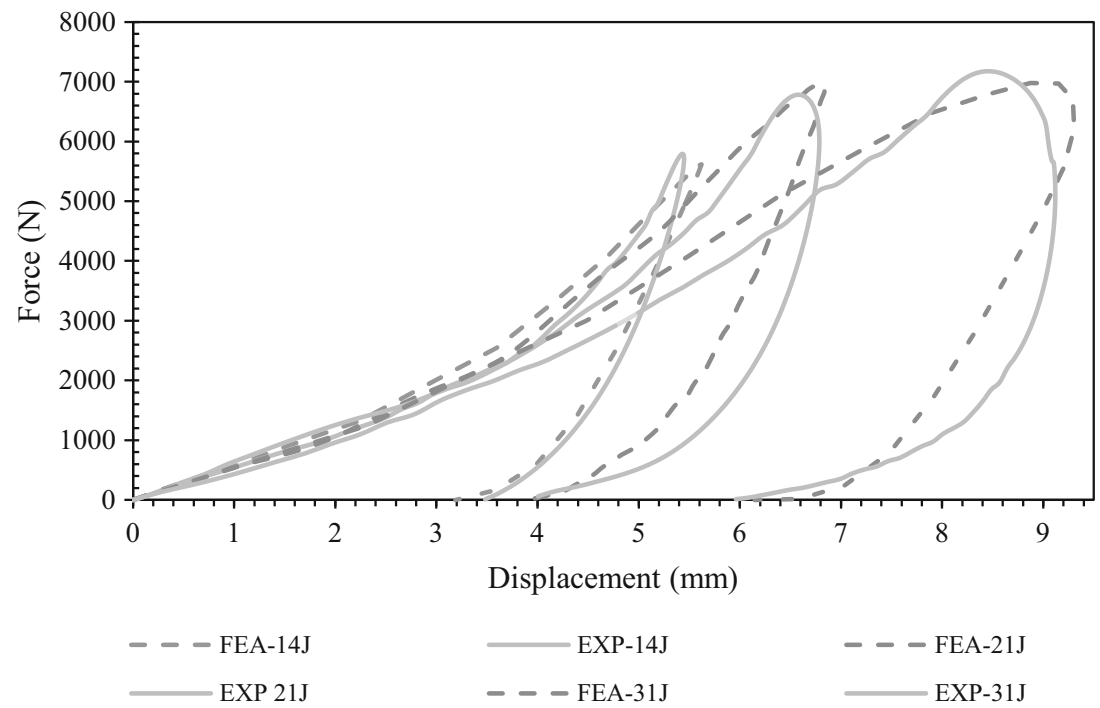


Fig. 8 Damage morphologies of CARALL specimens on impacted and non-impacted sides

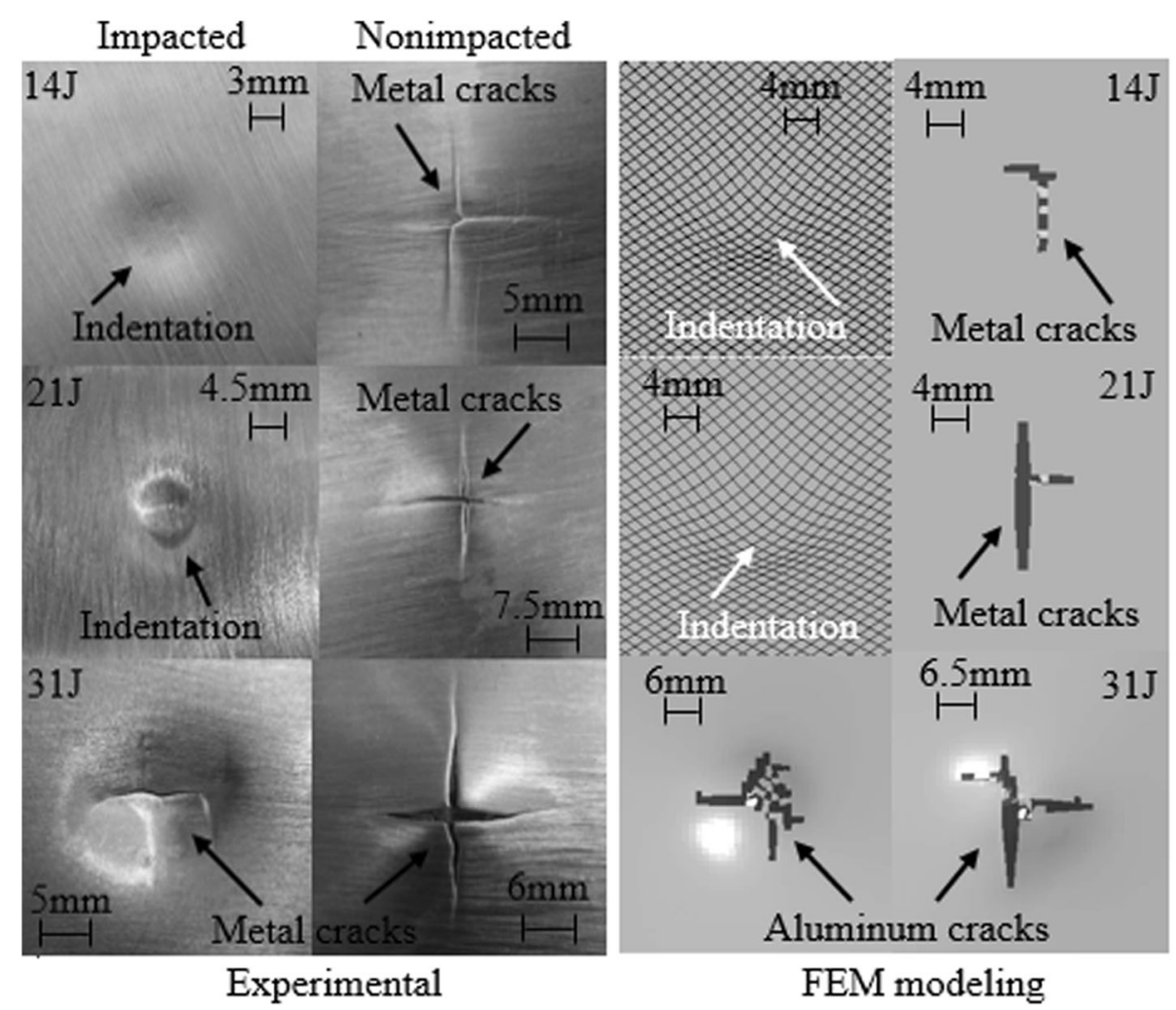

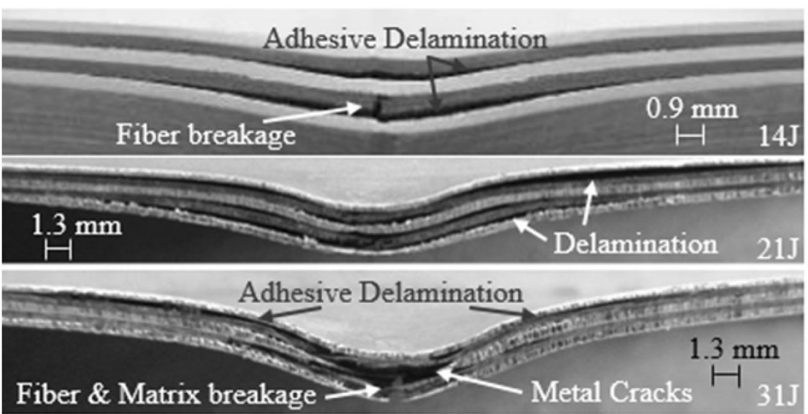

(a) Experimental

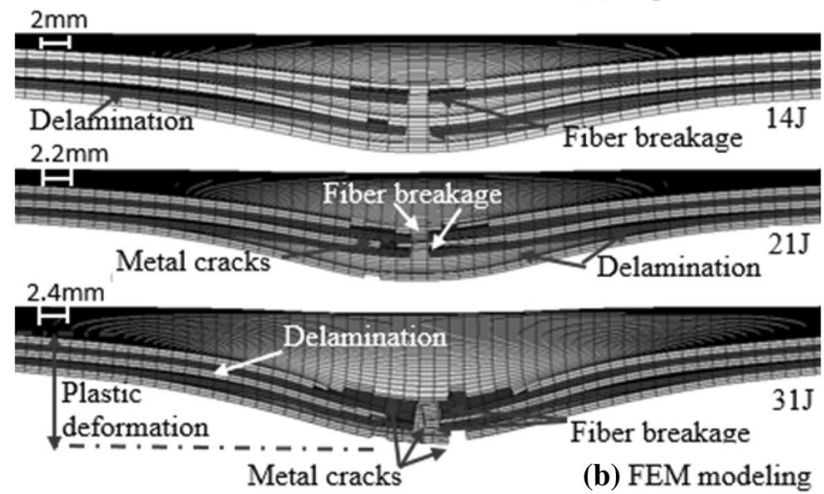

Fig. 9 Cross section images of CARALL-3/2 specimens under different impact energies captures the perforation failure of aluminum and CFRP layers at higher impact energy but overestimates the delamination area as represented by Fig. 10 .

Tensile failures prediction results of woven composite layers located near the impacted and non-impacted sides are shown in Fig. 11. The colors represent the damage degree of composite. While the blue represent that the damage is critical (value nearly 0.0), red represent that the damage has not occurred (value nearly 1.0), and others represent different damage states. As expected, damage in carbon fiber/epoxy layers increased with the increase in the impact energy.

Numerical simulation elucidated the extent of tensile damage in carbon fiber/epoxy layers. A correlation between experimental results and numerical prediction results was not achieved for the tensile failure of carbon fiber/epoxy layers due to difficultly of removing aluminum layers and characterize the damage in experimental samples. A comparison between experimental results and numerical predictions in terms of absorbed energy, energy restitution coefficient and delaminated area is shown by Fig. 12. Energy restitution coefficient was calculated for numerical and experimental results for each impact energy using the formula described by Eq. 14 . 
Fig. 10 Comparison between $\mathrm{C}$-scan and FEA predictions for delamination in CARALL specimens under different impact energies

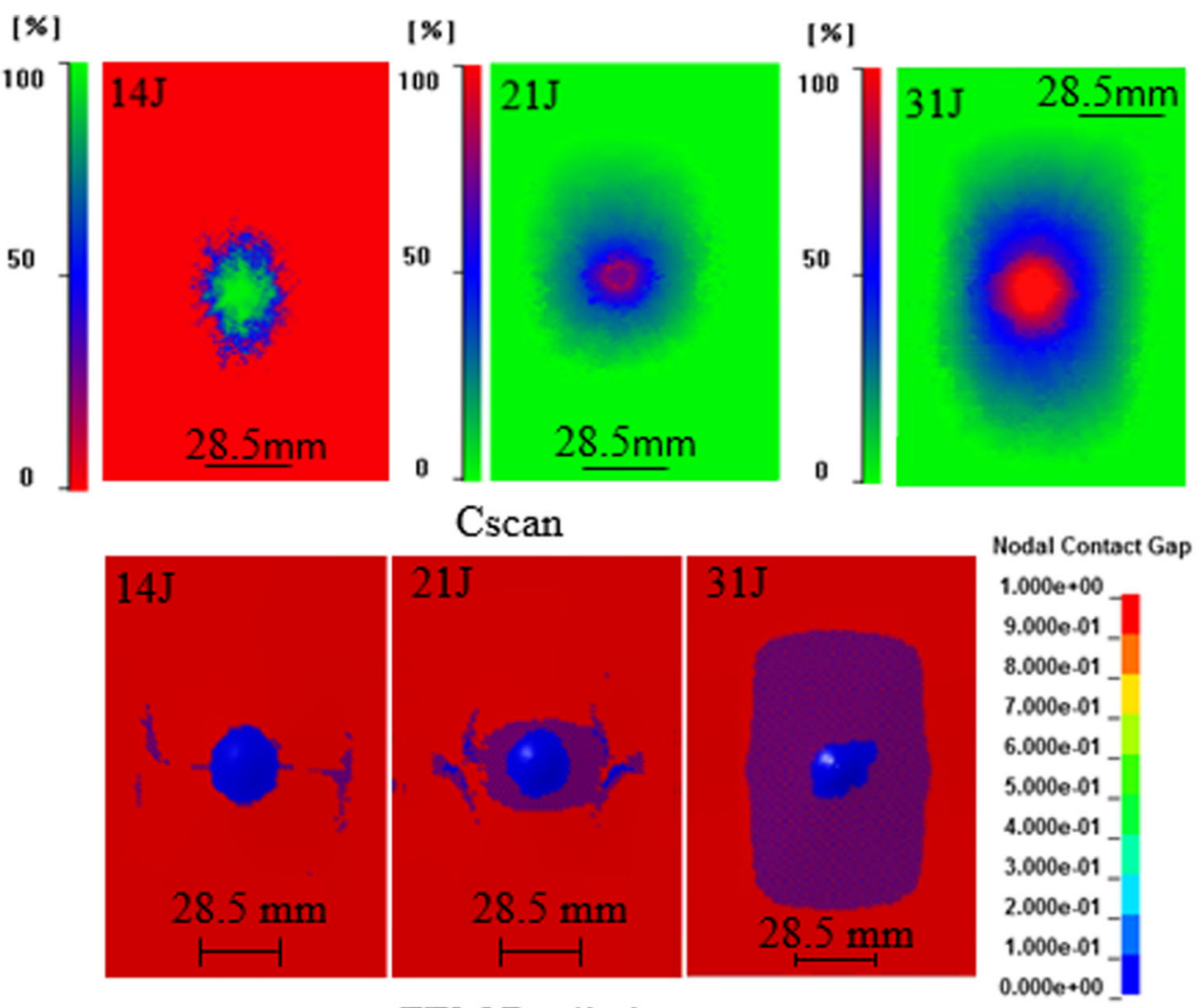

FEM Prediction

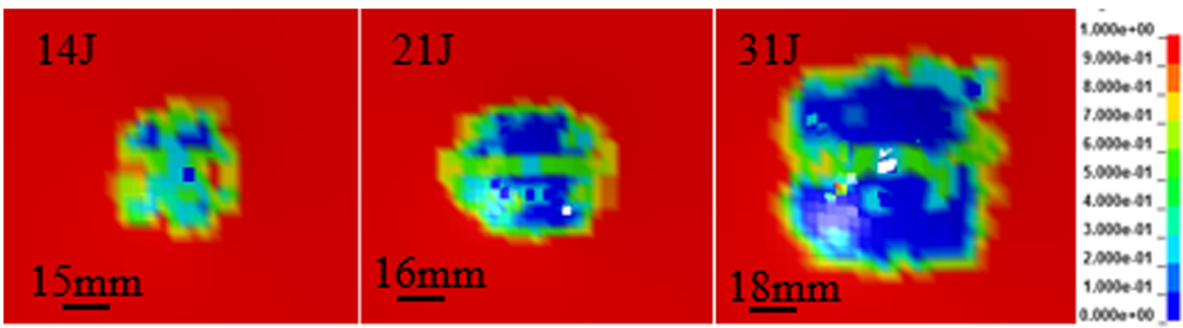

(a) Composite ply near impacted side

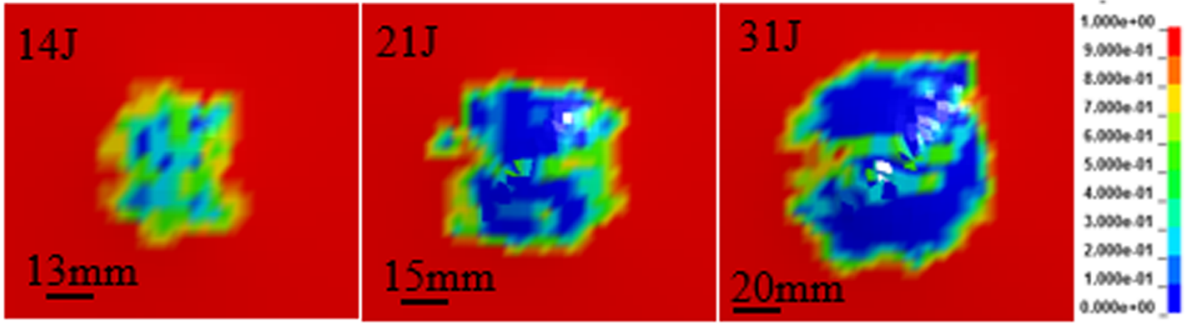

(b) Composite ply near non impacted side

Energy restitution coefficient (ERC)

$=1-\frac{\text { Absorbed energy }}{\text { Total Impact energy }}$

FEA material model predicted the energy absorption and damaged area results similar to experimental results at 14 and $21 \mathrm{~J}$ impact energies but showed discrepancies in results at $31 \mathrm{~J}$ impact energy. Similarly, the FEM model underestimated the energy restitution coefficient at higher impact energy but gives acceptable results at lower impact energies. The experimental results and numerical predictions of the impact induced crack lengths measured on the 
Fig. 12 Impact test results for CARALL specimens under different impact energies; a absorbed energy; b energy restitution coefficient; c delamination area

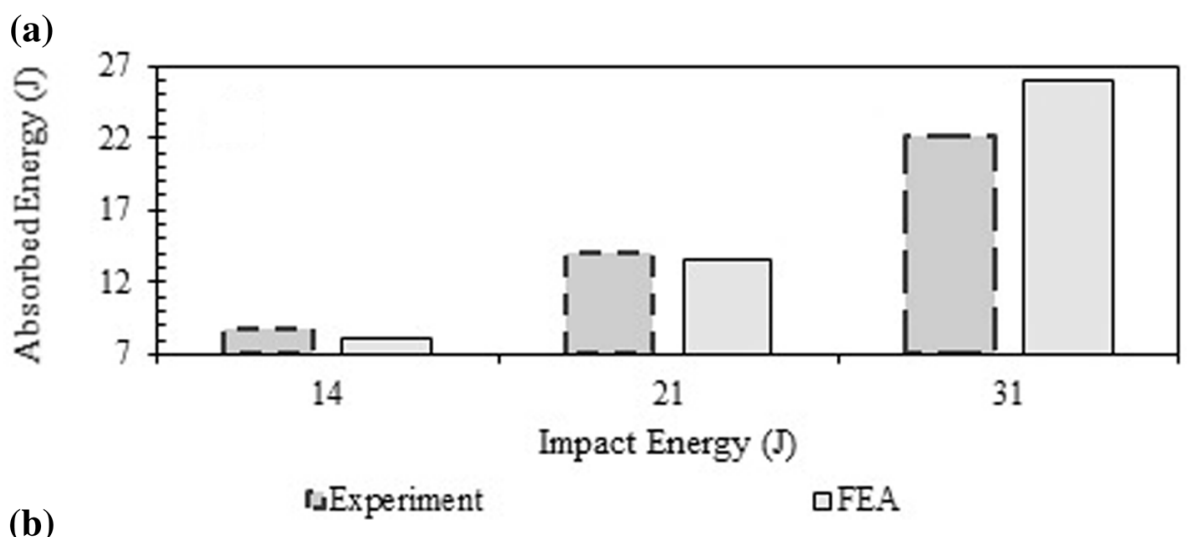

(b)

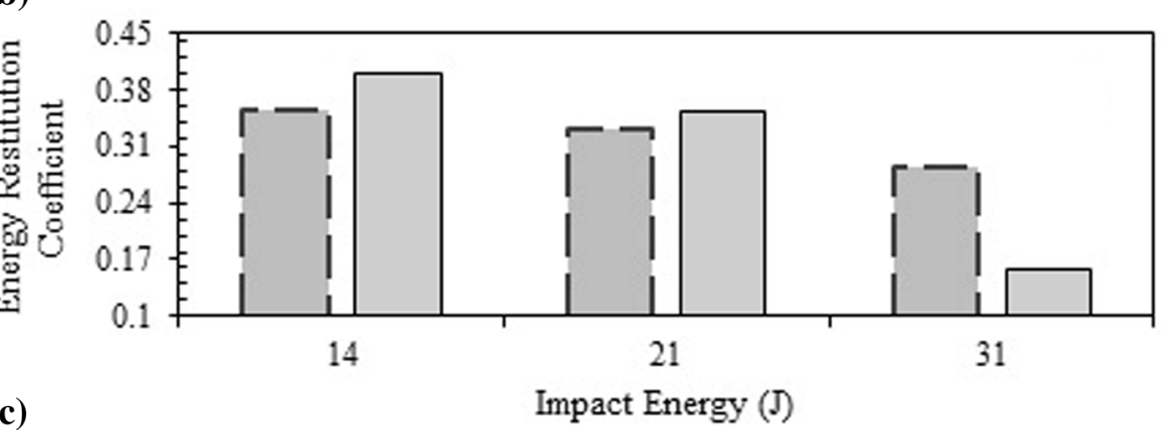

(c)

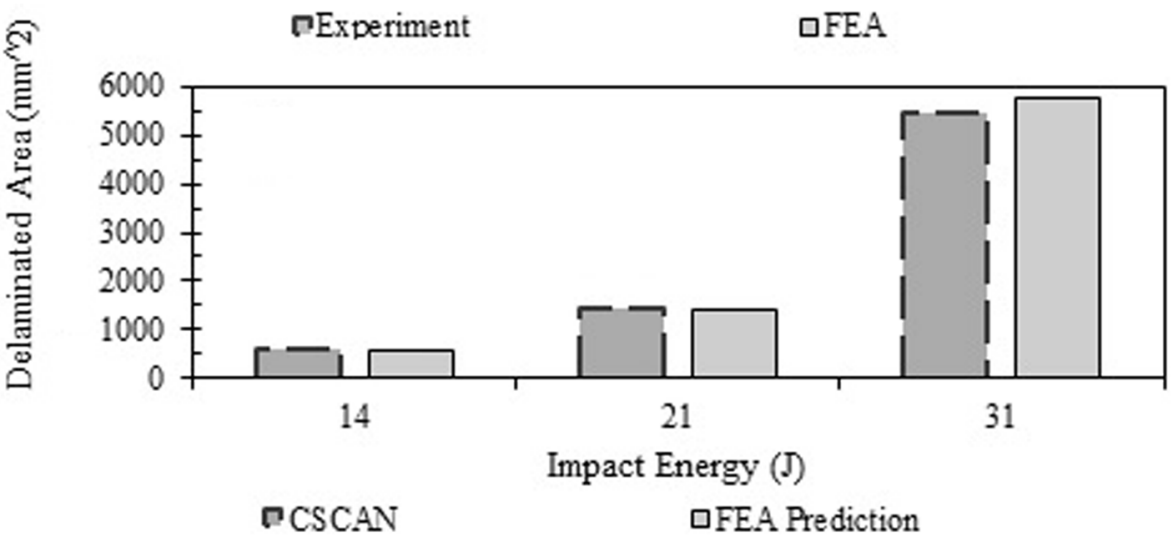

impacted side and the non-impacted side respectively, along with the ultimate central deflection in CARALL FMLs at various impact energies are summarized in Table 4.

Indentation induced damage with no cracks in aluminum layer on impacted side of specimens was found for 14 and $21 \mathrm{~J}$ impact energy, whereas a $18 \mathrm{~mm}$ long crack was found in aluminum layer along with indentation on impacted side for $31 \mathrm{~J}$ impact energy. The length of longest crack on the non-impacted side of specimens was measured to be 20,24 and $31 \mathrm{~mm}$ for 14,21 and $31 \mathrm{~J}$ impact energies respectively. Upon comparison between numerical predictions and experimental results, it was found that FEM model predicts the ultimate central deflection and crack lengths on impacted and non-impacted sides with acceptable accuracy level
The error sensitivities of the peak force, energy restitution coefficient and energy absorbed predictions as compared to the experimental results are shown in Table 5. The FEM model overestimates the absorbed energy value at higher impact energy resulting in a significant error, approximately equal to $17 \%$ as compared to experimental results.

\section{Conclusions}

In the present research, the impact performance of CARALL FMLs is investigated experimentally through drop weight test and dynamic finite element method based transient simulations. The numerical simulations using the above mentioned damage model successfully predict the low velocity impact behavior of CARALL FMLs. It was 
Table 4 Ultimate central deflection and crack lengths in outer layers

\begin{tabular}{|c|c|c|c|c|c|c|}
\hline \multirow[t]{3}{*}{ Impact energy $(\mathrm{J})$} & \multicolumn{4}{|c|}{ Crack lengths (mm) } & \multicolumn{2}{|c|}{ Ultimate central deflection $(\mathrm{mm})$} \\
\hline & \multicolumn{2}{|c|}{ Impacted side } & \multicolumn{2}{|c|}{ Non-impacted side } & \multirow[b]{2}{*}{ Experiment } & \multirow[b]{2}{*}{ Numerical } \\
\hline & Experiment & Numerical & Experiment & Numerical & & \\
\hline 14 & 0 & 0 & 20 & 17 & 5.45 & 5.61 \\
\hline 21 & 0 & 0 & 24 & 28 & 6.78 & 6.83 \\
\hline 31 & 18 & 20 & 31 & 34 & 9.11 & 9.31 \\
\hline
\end{tabular}

Table 5 Percent error in numerical predictions as compared to experimental Results

\begin{tabular}{|c|c|c|c|c|c|c|c|c|c|}
\hline \multirow[t]{3}{*}{ Impact energy $(\mathrm{J})$} & \multicolumn{6}{|c|}{ Force-displacement response } & \multirow{2}{*}{\multicolumn{3}{|c|}{ Absorbed energy $(\mathrm{J})$}} \\
\hline & \multicolumn{3}{|c|}{ Peak force $(\mathrm{N})$} & \multicolumn{3}{|c|}{ Energy restitution coefficient } & & & \\
\hline & Exp. & FEM & $\%$ Error & Exp. & FEM & $\%$ error & Exp. & FEM & $\%$ Error \\
\hline 14 & 5789 & 5616 & 2.98 & 0.3547 & 0.4011 & 13.1 & 8.75 & 8.12 & 7.2 \\
\hline 21 & 6777.8 & 6962 & 2.73 & 0.3313 & 0.3539 & 6.8 & 14.0 & 13.5 & 3.4 \\
\hline 31 & 7171 & 6980 & 2.66 & 0.2854 & 0.1597 & 44.1 & 22.15 & 26.0 & 17.6 \\
\hline
\end{tabular}

found that CARALL offers excellent impact resistance property due to the high stiffness of carbon fiber. As expected, it was found that the delaminated area increases with the impact energy to a level until the primary failure mode is changed from delamination to failure of carbon fiber/epoxy or metallic layers. A good correlation was found between numerical and experiment results for force-displacement, absorbed energy and energy restitution coefficients for 14 and $21 \mathrm{~J}$ impact energies but the slight difference was observed for $31 \mathrm{~J}$ impact energy which may be due to the failure of material model to successfully capture the system response in unloading region. Numerical material model successfully captured the peak load levels and ultimate central deflection for each impact energy level and compared well with the experimental results.

Acknowledgments This work was performed under Rumble Fellowship (2013-2014) and Ford's URP program.

\section{References}

1. Asundi A, Choi AYN (1997) Fiber metal laminates: an advanced material for future aircraft. $\mathrm{J}$ Mater Process Technol 63(1-3):384-394. doi:10.1016/S0924-0136(96)02652-0

2. Thomas J (2001) The A380 programme-the big task for Europe's aerospace industry. Air Space Eur 3(3-4):35-39. doi:10. 1016/S1290-0958(01)90050-4

3. Vlot A (2001) Historical overview. In: Vlot A, Gunnink J (eds) Fibre metal laminates. Springer, Netherlands, p 3-21. doi:10. 1007/978-94-010-0995-9_1

4. Krishnakumar S (1994) Fiber metal laminates-the synthesis of metals and composites. Material Manuf Process 9(2):295-354

5. Cantwell W (2000) The mechanical properties of fibre-metal laminates based on glass fibre reinforced polypropylene. Compos Sci Technol 60(7):1085-1094
6. Vogelesang LB, Vlot A (2000) Development of fibre metal laminates for advanced aerospace structures. J Mater Process Technol 103(1):1-5. doi:10.1016/S0924-0136(00)00411-8

7. Abdullah MR, Cantwell WJ (2006) The impact resistance of polypropylene-based fibre-metal laminates. Compos Sci Technol 66(11-12):1682-1693. doi:10.1016/j.compscitech.2005.11.008

8. Caprino G, Spataro G, Del Luongo S (2004) Low-velocity impact behaviour of fibreglass-aluminium laminates. Compos A Appl Sci Manuf 35(5):605-616. doi:10.1016/j.compositesa.2003.11. 003

9. Bieniaś J, Jakubczak P (2012) Low velocity impact resistance of aluminium/carbon-epoxy fiber metal laminates. Compos Theory Pract 12(3): 193-197

10. Song S, Byun Y, Ku T, Song W, Kim J, Kang B (2010) Experimental and numerical investigation on impact performance of carbon reinforced aluminum laminates. J Mater Sci Technol 26(4):327-332

11. Ye L, Lawcock G, Mai Y, Sun C (1997) Effects of fibre/matrix adhesion on carbon-fibre-reinforced metal laminates. I. Residual strength. Compos Sci Technol 57(12):1609-1619

12. Kim HS, Kim BC, Lim TS (2004) Foreign objects impact damage characteristics of aluminum/composite hybrid drive shaft. Compos Struct 66(1):377-389

13. Yu G-C, Wu L-Z, Ma L, Xiong J (2015) Low velocity impact of carbon fiber aluminum laminates. Compos Struct 119:757-766

14. Jaroslaw B, Barbara S, Patryk J (2014) The comparison of low velocity impact resistance of aluminum/carbon and glass fiber metal laminates. Polym Compos. doi:10.1002/pc.23266

15. Rajkumar G, Krishna M, Murthy HN, Sharma S, Mahesh KV (2012) Investigation of repeated low velocity impact behaviour of GFRP/Aluminium and CFRP/Aluminium laminates. Int $\mathrm{J}$ Soft Comput Eng 1(6):50-58

16. ASTM D7136/D7136M-15 (2015) Standard test method for measuring the damage resistance of a fiber-reinforced polymer matrix composite to a drop-weight impact event. ASTM International, West Conshohocken

17. Livermore Software Technology Corporation, LS DYNA Version 971, Theory Manual

18. http://www.atlassteels.com.au/documents/Atlas_Aluminium_data sheet_5052_rev_Oct_2013.pdf 
19. http://cytec.com/sites/default/files/datasheets/VTM260_series.pdf

20. Chang F-K, Chang K-Y (1987) A progressive damage model for laminated composites containing stress concentrations. J Compos Mater 21(9):834-855

21. Livermore Software Technology Corporation, LS DYNA Version 971, Keyword User's Manual, Vol II, Material Models

22. Hellen TK (1975) On the method of virtual crack extensions. Int J Numer Methods Eng 9(1):187-207. doi:10.1002/nme. 1620090114

23. Rice JR (1968) A path independent integral and the approximate analysis of strain concentration by notches and cracks. J Appl Mech 35(2):379-386

24. Rybicki EF, Kanninen M (1977) A finite element calculation of stress intensity factors by a modified crack closure integral. Eng Fract Mech 9(4):931-938

25. Raju I (1987) Calculation of strain-energy release rates with higher order and singular finite elements. Eng Fract Mech 28(3):251-274

26. Parks DM (1974) A stiffness derivative finite element technique for determination of crack tip stress intensity factors. Int J Fract 10(4):487-502

27. Griffith AA (1921) The phenomena of rupture and flow in solids. Philos Trans R Soc Lond Ser A 221:163-198

28. Gordnian K, Hadavinia H, Mason P, Madenci E (2008) Determination of fracture energy and tensile cohesive strength in Mode I delamination of angle-ply laminated composites. Compos Struct 82(4):577-586

29. Hillerborg A, Modéer M, Petersson P-E (1976) Analysis of crack formation and crack growth in concrete by means of fracture mechanics and finite elements. Cement Concr Res 6(6):773-781

30. Needleman A (1987) A continuum model for void nucleation by inclusion debonding. J Appl Mech 54(3):525-531

31. Tvergaard V, Hutchinson JW (1992) The relation between crack growth resistance and fracture process parameters in elasticplastic solids. J Mech Phys Solids 40(6):1377-1397
32. Tvergaard V, Hutchinson JW (1993) The influence of plasticity on mixed mode interface toughness. J Mech Phys Solids 41(6):1119-1135

33. Camacho GT, Ortiz M (1996) Computational modelling of impact damage in brittle materials. Int $\mathbf{J}$ Solids Struct 33(20):2899-2938

34. Mi Y, Crisfield M, Davies G, Hellweg H (1998) Progressive delamination using interface elements. J Compos Mater 32(14):1246-1272

35. Hillerborg A (1991) Application of the fictitious crack model to different types of materials. Int J Fract 51(2):95-102

36. Bala S (2010) Tie-break contacts in LS-DYNA. Livermore Software Technology Corporation, Livermore

37. Tsartsaris N, Meo M, Dolce F, Polimeno U, Guida M, Marulo F (2011) Low-velocity impact behavior of fiber metal laminates. J Compos Mater, p 0021998310376108

38. Livermore Software Technology Corporation, LS DYNA Version 971, Keyword User's Manual

39. Lemmen P, Meijer G, Rasmussen E (1999) Dynamic behavior of composite ship structures (DYCOSS) failure prediction tool. In: 70th shock and vibration symposium. p 15-19

40. Meijer G, Rasmussen E, Lemmen P, Lemmen R, Palmer D (1999) Dynamic behavior of composite ship structures (DYCOSS); tests and analyses efforts. In: 70th shock and vibration symposium. p 15-19

41. Lemmen P, Meijer G (2001) Failure prediction tool theory and user manual. TNO Report

42. Benzeggagh M, Kenane M (1996) Measurement of mixed-mode delamination fracture toughness of unidirectional glass/epoxy composites with mixed-mode bending apparatus. Compos Sci Technol 56(4):439-449

43. Shin DK, Kim HC, Lee JJ (2014) Numerical analysis of the damage behavior of an aluminum/CFRP hybrid beam under three point bending. Compos B Eng 56:397-407 